\title{
Atmospheric Oxidation \\ of a Gold-Copper Float Concentrate
}

\author{
Ruslan N. Nabiulin*, Andrey V. Bogorodsky, \\ Stanislav V. Balikov and Yuriy E. Emelyanov \\ Irkutsk Research Institute of Precious and Rare Metals \\ and Diamonds IRGIREDMET JSC \\ 38 Gagarina Str., Irkutsk, 664025, Russia
}

Received 28.02.2017, received in revised form 14.03.2017, accepted 23.03.2017

The article presents the results of atmospheric oxidation of a gold-copper float concentrate with different size particles, oxidation time, oxygen and air blow. It was shown that atmospheric oxidation of a concentrate increases gold and copper recovery, reduces reagent consumption in subsequent cyanidation.

Keywords: gold-copper sulphide float concentrate, atmospheric oxidation, cyanidation, elemental sulphur, tennantite.

DOI: $10.17516 / 1998-2836-0013$.

\section{Атмосферное окисление золотомедного флотоконцентрата}

\author{
Р.Н. Набиулин, А.В. Богородский, \\ С.В. Баликов, Ю.Е. Емельянов \\ Россия, 664025, Иркутск, ул. Гагарина, 38
}

Иркутский научно-исследовательский институт благородных и редких металлов и алмазов $А О$ «Иргиредмет»

Представлены результаты исследований по атмосферному окислению золотомедного флотоконцентрата при различной крупности, продолжстельности окисления, продувки кислородом и воздухом. Показано, что атмосферное окисление флотоконцентрата повымает извлечение золота и меди и снижает расходы реагентов при последующем иианировании.

(C) Siberian Federal University. All rights reserved

* Corresponding author E-mail address: nabiulinrus@mail.ru 
Ключевые слова: сульфидный золотомедный флотоконцентрат, атмосферное окисление, иианирование, элементарная сера, теннантит.

\section{Введение}

Переработка сульфидных золотомедных руд и концентратов по классической цианистой технологии приводит к высоким расходам реагентов и низкому извлечению золота. Для повышения эффективности процесса извлечения драгоценных металлов необходимо разрушить сульфидные минералы и извлечь медь из продукта переработки перед цианированием, что позволит снизить расходы основных реагентов.

Перспективным способом переработки упорных золотомедных концентратов является атмосферное окисление сульфидов при температуре $90-95{ }^{\circ} \mathrm{C}$, в кислой или щелочной среде, с барботажем кислорода или воздуха.

\section{Характеристика золотомедного флотоконцентрата}

Исследования проведены на упорном золотомедном флотоконцентрате одного из месторождений Урала. Сульфидная составляющая исследуемого флотоконцентрата состоит из пирита (36,6 \%), теннантита $(6,18 \%)$ и халькопирита $(3,0 \%)$. Содержание меди во флотоконцентрате составляет 4,3\%. Железо (18,3\%), мышьяк (1,26 \%) и сера $(22,8 \%)$ в основном представлены сульфидной формой (рис. 1, 2). На рис. 3 изображен фазовый анализ на золото.

\section{Реакции окисления сульфидов}

В процессе атмосферного окисления (АО) протекают следующие реакции окисления сульфидов [1-11].

Окисление пирита происходит с образованием сульфата железа (1) и при низких температурах с образованием элементарной серы (2), часть которой переходит в серную кислоту:

$$
\mathrm{FeS}_{2}+3,75 \mathrm{O}_{2}+0,5 \mathrm{H}_{2} \mathrm{O}=0,5 \mathrm{Fe}_{2}\left(\mathrm{SO}_{4}\right)_{3}+0,5 \mathrm{H}_{2} \mathrm{SO}_{4} ; \Delta \mathrm{G}=-1144,02 \text { кДж/моль, }
$$

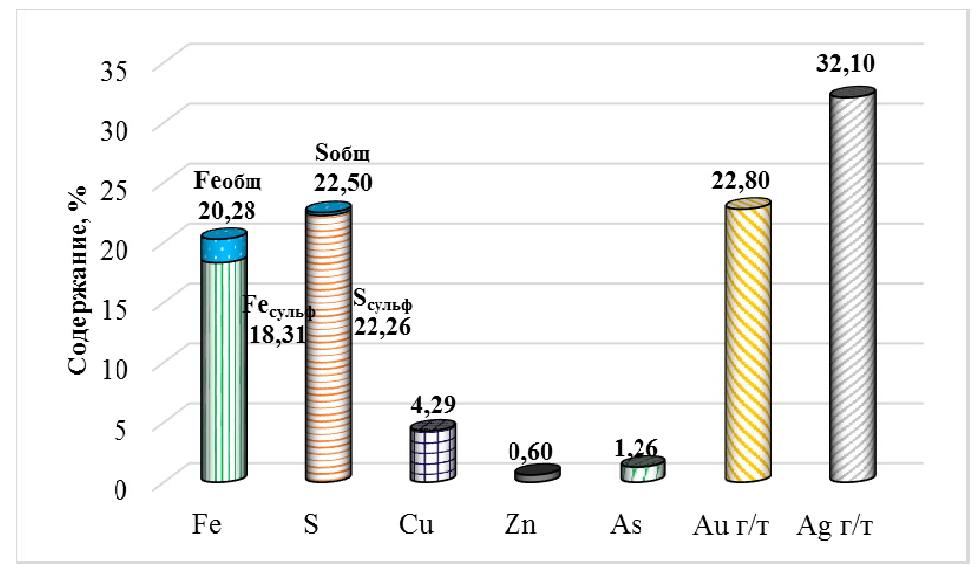

Рис. 1. Химический состав сульфидного золотомедного флотоконцентрата 


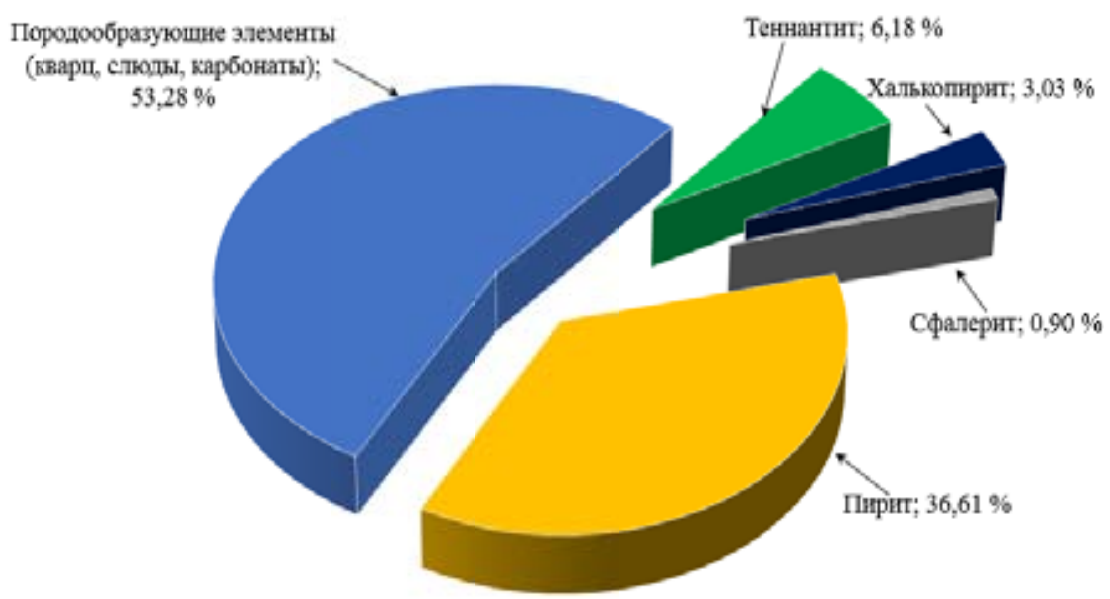

Рис. 2. Рациональный состав сульфидного золотомедного флотоконцентрата

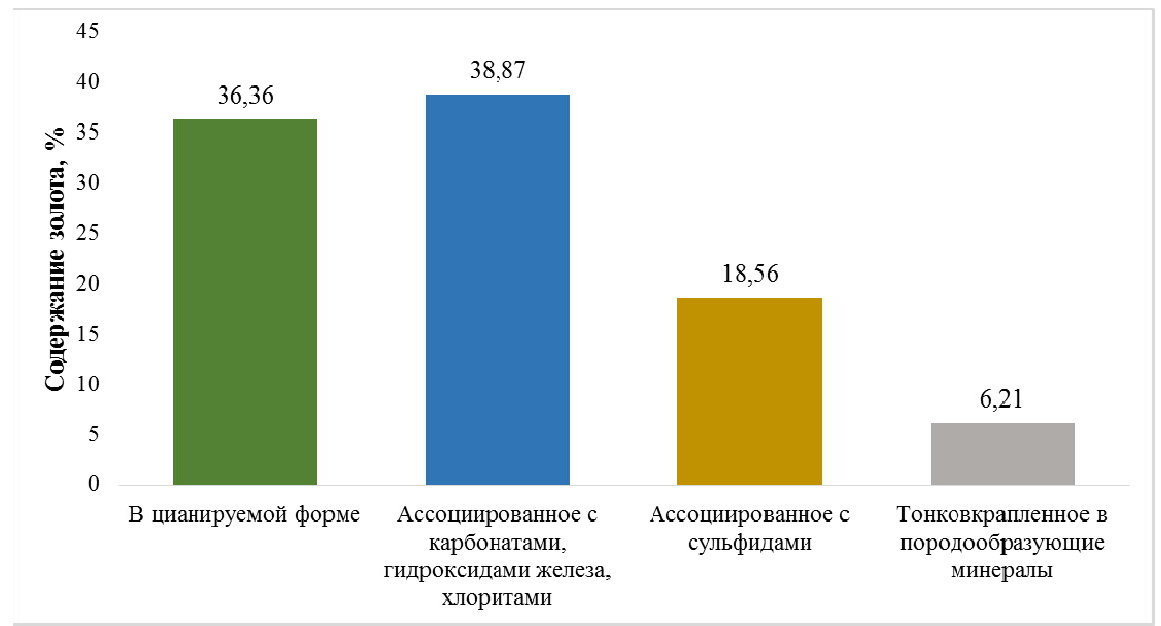

Рис. 3. Фазовый анализ сульфидного золотомедного флотоконцентрата на золото

$$
\mathrm{FeS}_{2}+2,25 \mathrm{O}_{2}+0,5 \mathrm{H}_{2} \mathrm{SO}_{4}=0,5 \mathrm{Fe}_{2}\left(\mathrm{SO}_{4}\right)_{3}+0,5 \mathrm{H}_{2} \mathrm{O}+\mathrm{S} ; \Delta \mathrm{G}=-585,99 \text { кДж/моль. }
$$

Окисление теннантита также сопровождается образованием элементарной серы $(3,4)$, однако ее количество в разы больше, чем при окислении пирита. Медь переходит в раствор в виде медного купороса, как и при окислении халькопирита $(5,6)$. Часть мышьяка остается в твердом продукте в виде скородита, остальная часть образует мышьяковистую кислоту и остается в жидком остатке.

Окисление халькопирита:

$$
\begin{aligned}
& 2 \mathrm{Cu}_{12} \mathrm{As}_{4} \mathrm{~S}_{13}+59,5 \mathrm{O}_{2}+13 \mathrm{H}_{2} \mathrm{O}=24 \mathrm{CuSO}_{4}+\mathrm{H}_{2} \mathrm{SO}_{4}+8 \mathrm{H}_{3} \mathrm{AsO}_{4}+\mathrm{S} ; \Delta \mathrm{G}= \\
& =-7648,94 \text { кДж/моль, } \\
& \mathrm{Cu}_{12} \mathrm{As}_{4} \mathrm{~S}_{13}+18,5 \mathrm{O}_{2}+7 \mathrm{H}_{2} \mathrm{SO}_{4}=12 \mathrm{CuSO}_{4}+4 \mathrm{H}_{3} \mathrm{AsO}_{4}+\mathrm{H}_{2} \mathrm{O}+8 \mathrm{~S} ; \Delta \mathrm{G}= \\
& =-595,83 \text { кДж/моль, }
\end{aligned}
$$




$$
\begin{aligned}
& \mathrm{CuFeS}_{2}+\mathrm{O}_{2}+2 \mathrm{H}_{2} \mathrm{SO}_{4}=\mathrm{CuSO}_{4}+\mathrm{FeSO}_{4}+2 \mathrm{~S}+2 \mathrm{H}_{2} \mathrm{O} ; \Delta \mathrm{G}=-335,75 \text { кДж/моль, } \\
& \mathrm{CuFeS}_{2}+1,25 \mathrm{O}_{2}+2,5 \mathrm{H}_{2} \mathrm{SO}_{4}=\mathrm{CuSO}_{4}+0,5 \mathrm{Fe}_{2}\left(\mathrm{SO}_{4}\right)_{3}+2 \mathrm{~S}+2,5 \mathrm{H}_{2} \mathrm{O} ; \\
& \Delta \mathrm{G}=-435,85 \text { кДж/моль. }
\end{aligned}
$$

Окисление сфалерита:

$$
\mathrm{ZnS}+0,5 \mathrm{O}_{2}+\mathrm{H}_{2} \mathrm{SO}_{4}=\mathrm{ZnSO}_{4}+\mathrm{S}+\mathrm{H}_{2} \mathrm{O} ; \Delta \mathrm{G}=-211,26 \text { кДж/моль. }
$$

Цинк после окисления практически весь извлекается в раствор.

Целью исследований по атмосферному окислению золотомедного флотоконцентрата являлось получение твердого золотосодержащего продукта, пригодного для извлечения золота методом цианирования и перевод меди в сернокислый раствор с последующим выделением в товарный продукт способом жидкостной экстракции.

\section{Методика проведения исследований}

\section{по атмосферному окислению золотомедного флотоконцентрата}

Исследования по атмосферному окислению флотоконцентрата проведены в титановом реакторе при температуре $90-95^{\circ} \mathrm{C}$ и атмосферном давлении кислорода или воздуха, с начальной концентрацией $\mathrm{H}_{2} \mathrm{SO}_{4}-100$ г/л, предварительно флотоконцентрат доизмельчали в бисерной мельнице. Для удаления образовавшейся элементной серы и связанного с ней эффекта «пассивации золота» окисленный флотоконцентрат подвергали горячей известковой обработке при соотношение Ж:T=4:1, температуре $80-90{ }^{\circ} \mathrm{C}$, с загрузкой $\mathrm{CaO} 80$ кг/т. Окисленные продукты цианировали в агитационном режиме (рис. 4).

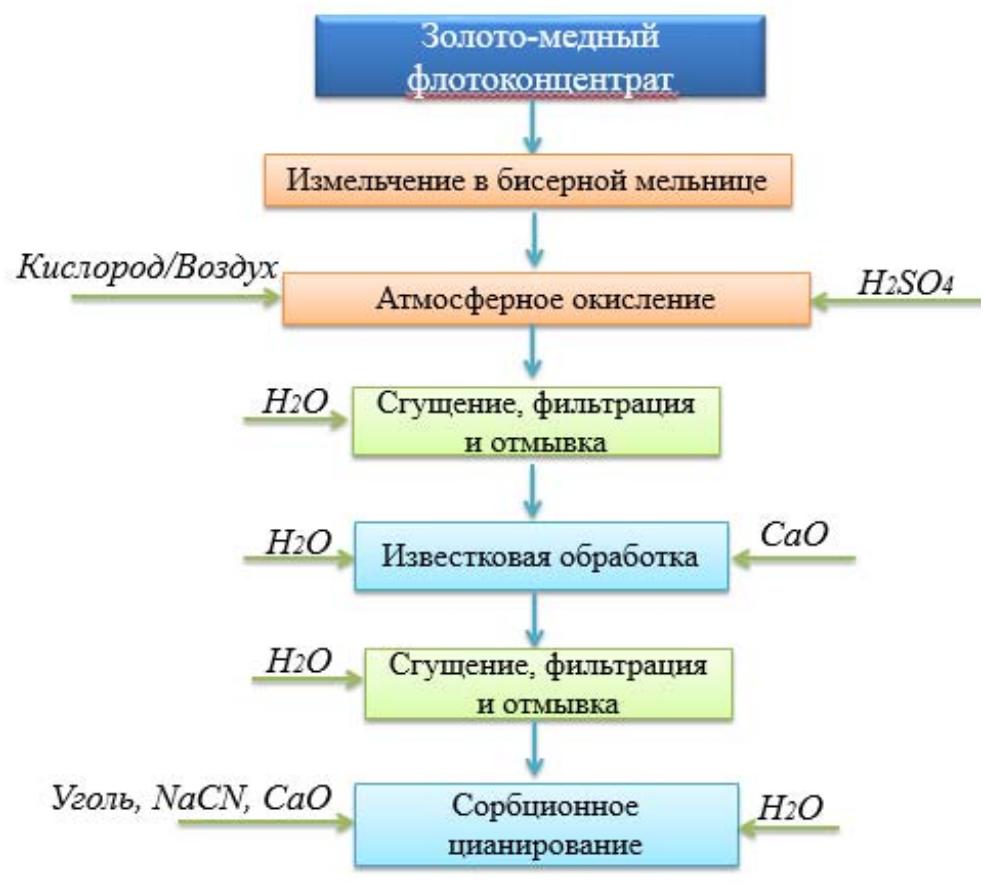

Рис. 4. Блок-схема атмосферного окисления золотомедного флотоконцентрата 
Эффективность атмосферного окисления оценивали по степени разложения сульфидов, извлечению меди в сернокислые растворы и по результатам цианирования твердых продуктов атмосферного окисления.

\section{Определение влияния крупности золотомедного флотоконцентрата на технологические показатели атмосферного окисления}

Окисление флотоконцентрта проводили на исходной крупности $\left(\mathrm{P}_{98} \%=-74\right.$ мкм) с продувкой кислородом и воздухом. Результаты исследований представлены в табл. 1.

Полученные данные свидетельствуют о низкой степени окисления. Извлечение меди в раствор составляет $48 \%$, золота - $86 \%$.

На рис. 5-7 представлены результаты исследования по атмосферному окислению с дальнейшим цианированием при различной крупности флотоконцентрата.

Результаты исследований показали, что доизмельчение материала до 20 мкм позволяет увеличить извлечение золота до $95 \%$ и снизить расход $\mathrm{NaCN}$ за счет увеличения извлечения меди в раствор при атмосферном окислении.

Показано, что с увеличением продолжительности атмосферного окисления увеличивается степень окисления сульфидов и извлечение меди в раствор АО. Установлено, что при атмосферном окислении с продувкой кислорода степень окисления сульфидов возрастает, а извлечение меди в раствор снижается. В то же время извлечение железа в раствор увеличивается. При измельчении концентрата происходит активация пирита, который «забирает» на себя избыток кислорода, снижая степень окисления теннантита и, соответственно, извлечение меди. При окислении с продувкой воздухом извлечение меди протекает интенсивнее, а извлечение железа в раствор снижается. Установлено, что при продувке через пульпу воздуха происходит преимущественно окисление теннантита, окисление пирита протекает лишь на 8-10\% (рис. 8-11).

Максимально достигнутое извлечение меди в раствор составило 88,6 \%.

Таблица 1. Атмосферное окисление золотомедного флотоконцентрата исходной крупности

\begin{tabular}{|c|c|c|c|c|c|c|c|c|c|}
\hline \multirow{2}{*}{ Опыт } & \multirow{2}{*}{$\tau, \mathbf{\Psi}$} & \multirow{2}{*}{$\begin{array}{c}\text { Окислитель } \\
\mathrm{O}_{2} / \text { воздух }\end{array}$} & \multicolumn{4}{|c|}{ Концентрация в жидкой фазе, г/л } & \multirow{2}{*}{$\begin{array}{c}\text { Извлечение } \\
\mathrm{Cu}, \%\end{array}$} & \multirow{2}{*}{$\begin{array}{c}\text { Извлечение } \\
\mathrm{Au,} \mathrm{\%}\end{array}$} & \multirow{2}{*}{$\begin{array}{c}\text { Расход } \\
\mathrm{NaCN}, \\
\kappa г / \mathrm{T}\end{array}$} \\
\hline & & & $\mathrm{H}_{2} \mathrm{SO}_{4}$ & $\mathrm{Fe}^{3+}$ & $\mathrm{Fe}^{2+}$ & As & & & \\
\hline 1 & 2 & \multirow{5}{*}{ воздух } & 100,5 & 1,0 & 0,1 & 0,1 & 5 & 74 & 19,0 \\
\hline 2 & 4 & & 102,3 & 1,9 & 0,3 & 0,2 & 10 & 77 & 13,0 \\
\hline 3 & 6 & & 105,6 & 2,5 & 0,5 & 0,2 & 20 & 80 & 10,0 \\
\hline 4 & 8 & & 107,8 & 3,1 & 0,6 & 0,2 & 35 & 84 & 8,9 \\
\hline 5 & 12 & & 121,6 & 3,7 & 0,7 & 0,2 & 48 & 86 & 8,0 \\
\hline 6 & 2 & \multirow{5}{*}{ кислород } & 100,1 & 0,3 & 0,1 & 0,1 & 3 & 71 & 20,0 \\
\hline 8 & 4 & & 101,8 & 0,6 & 0,3 & 0,1 & 9 & 73 & 14,2 \\
\hline 9 & 6 & & 103,4 & 0,7 & 0,4 & 0,1 & 18 & 76 & 11,0 \\
\hline 10 & 8 & & 105,1 & 0,8 & 0,5 & 0,1 & 32 & 79 & 10,0 \\
\hline 11 & 12 & & 122,8 & 0,8 & 0,6 & 0,2 & 43 & 82 & 8,6 \\
\hline
\end{tabular}




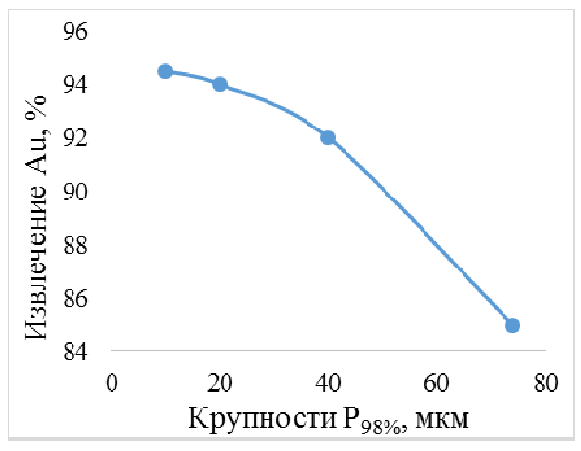

Рис. 5. Зависимость извлечения Аu от крупности флотоконцентрата

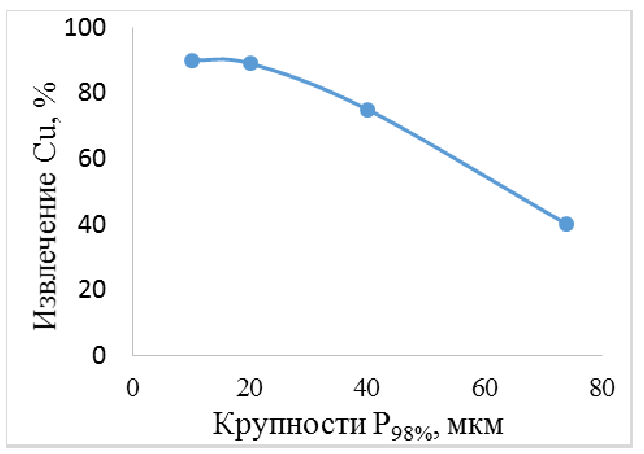

Рис. 6. Зависимость извлечения $\mathrm{Cu}$ от крупности флотоконцентрата

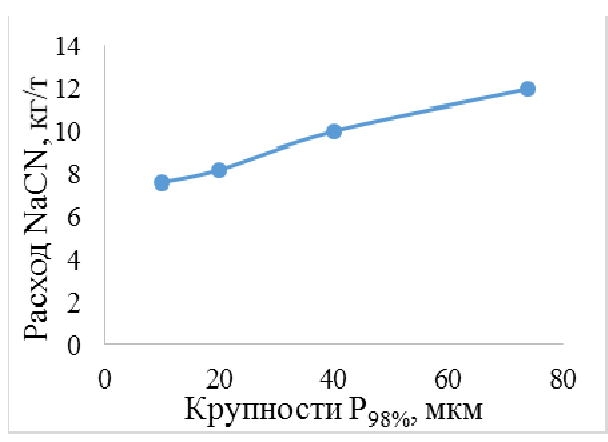

Рис. 7. Зависимость расхода $\mathrm{NaCN}$ от крупности флотоконцентрата



Рис. 8. Зависимость извлечения золота от продолжительности АО

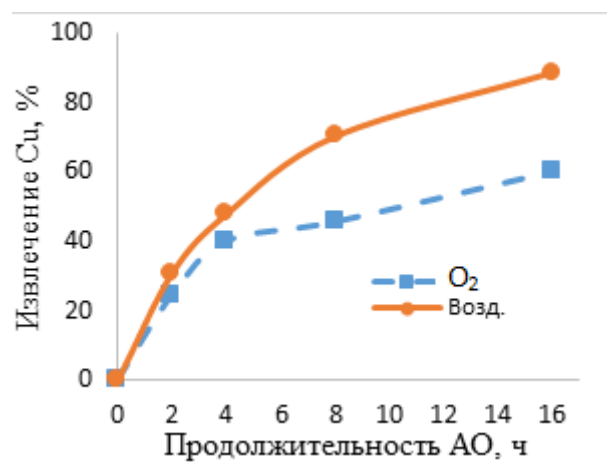

Рис. 9. Зависимость извлечения меди от продолжительности АО

Установлено, что при измельчении золотомедного флотоконцентрата извлечение золота из кеков атмосферного окисления не зависит от продолжительности и степени окисления. Извлечение золота зависит от крупности материала и подаваемого окислителя: $\mathrm{O}_{2} /$ воздух. Так, при цианировании измельченного флотоконцентрата извлечение золота составило 92-95 \% при продувке кислородом и 82-90 \% при продувке воздухом. Таким образом, извлечение золота 


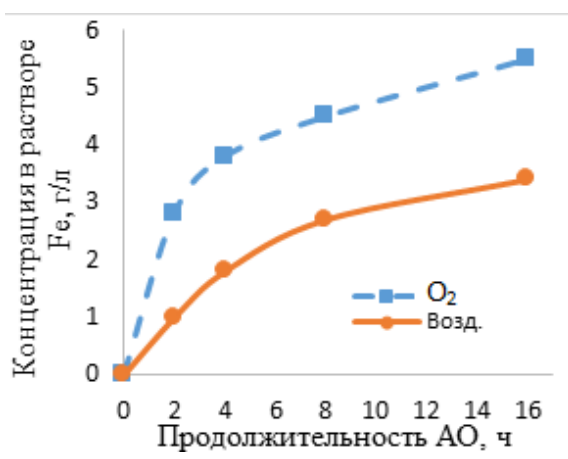

Рис. 10. Зависимость концентрации железа в растворе от продолжительности АО

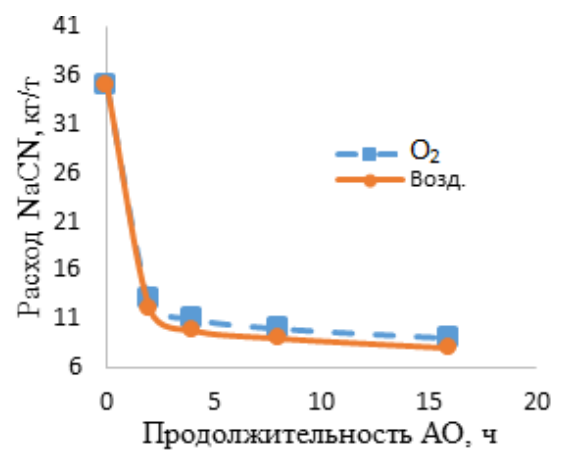

Рис. 11. Зависимость расхода цианида от продолжительности АО

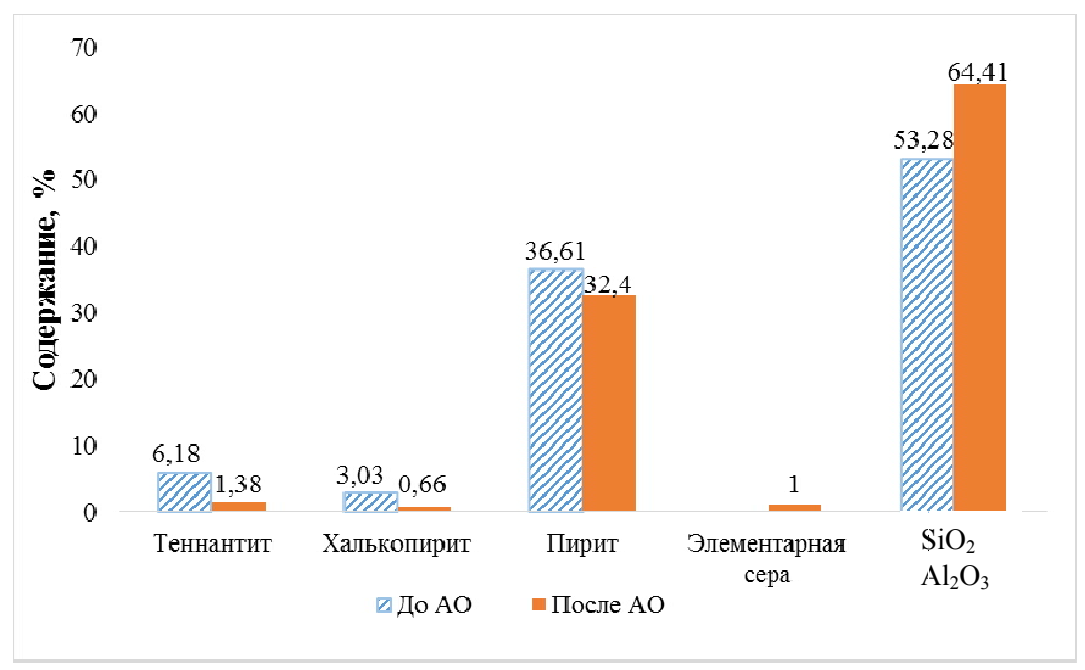

Рис. 12. Содержание сульфидных минералов до и после атмосферного окисления флотоконцентрата

при использовании кислорода в процессе атмосферного окисления на 2-5 \% выше, чем при использовании воздуха.

На рис. 12 представлено содержание сульфидных минералов до и после атмосферного окисления.

В процессе атмосферного окисления тонкоизмельченного флотоконцентрата происходит окисление медных минералов на 80-90 \%, пирита на 10 \% с образованием элементарной серы.

\section{Выводы}

Показано, что в процессе атмосферного окисления тонкоизмельченного флотоконцентрата происходит окисление медных минералов на 80-90 \%, арсенопирита на 60-80 \% и пирита не более чем на $10-15 \%$.

Установлено, что атмосферное окисление позволяет повысить извлечение золота на 59 \% (с 36 до 95 \%) и снизить расход $\mathrm{NaCN}$ на 21 кг/т (с 30 до 9 кг/т).

$$
-145-
$$




\section{Список литературы}

1. Лодейщиков, В.В. Технология извлечения золота и серебра из упорных руд, в 2-х томах. Иркутск: АО «Иргиредмет», 1999, 788 с. [Lodeyshchikov V.V. Technology of gold and silver recovery from refractory ores. In 2 volumes. Irkutsk: JSC Irgiredmet, 1999. (In Russ.)]

2. Demarthe J.M., Gandon L., Georgeaux A. A new hydrometallurgical process for copper. In: Yannopoulos J.C., Agarwal J.C. (Eds.). Extractive Metallurgy of Copper. The Minerals, Metal and Materials Society. Warrendale, Pennsylvania. 1976. 825 p.

3. Eduardo A. Brocchi, Rodrigo F.M. de Souza, Amanda L.T. Brandão, Carlos Augusto R. Queiróz, J.B. de Campos. Roasting of a copper sulphide concentrate. Proceedings of XXV International Mineral Processing Congress, Australia, Brisbane, 2010.

4. Sole K.C., Zárate G., Steeples J., Tinkler O., Robinson T.G. Global survey of copper solvent extraction operations and practices. Copper International Conference, December 1-4, 2013, Santiago, Chile. Vol. IV. P. 137-148.

5. Сенченко А.Е. Инновационная технология вскрытия тонко вкрапленного золота из упорного сульфидного сырья на основе сверхтонкого измельчения и атмосферного окисления. Материаль международной конференции «VIII Конгресс обогатителей стран СНГ», МИСИС, 2011. С. 291-296. [Senchenko A.E Innovative technology for recovery finely disseminated gold from refractory sulfide ores using ultrafine grinding and atmospheric oxidation. Proceedings of 8 th Congress of Ore-Dressers in the Countries of the CIS, MISIS, 2011, P. 291-296. (In Russ.)]

6. Аксёнов А.В., Васильев А.А. Сверхтонкое измельчение и атмосферное окисление как альтернативный способ вскрытия тонко вкрапленного золота из упорного сульфидного сырья. Инновационные процессы в технологиях комплексной переработки минерального и нетрадиционного сырья (Плаксинские чтения): Материалы международного совещания. Новосибирск 05-10 октября 2009. С. 100-101. [Aksenov A.V. Ultrafine grinding and atmospheric oxidation as an alternative approach to finely disseminated gold liberation from refractory sulphide materials. Proceedings of International Conference "Scientific basis and modern processes of refractory mineral raw materials complex processing” (Plaksin's Discourse 2009). Novosibirsk, October 05-10, 2009. P. 100-101. (In Russ.).]

7. Ващенко Г.А, Гудков С.С., Емельянов Ю.Е., Богородский А.В. Совершенствование технологии переработки золотосодержащей руды Березняковского месторождения. Обогащение руд 2014. 6, C. 7-10. [Vashchenko G.A, Gudkov S.S., Yemelyanov Yu. E., Bogorodsky A.V. Technological advancement in gold-containing ore processing from Bereznyakovskoe mine. Ore processing 2014, Vol. 6, 2014, P. 7-10. (In Russ.)]

8. Ochromowicz K., Chmielewski T. Solvent extraction in hydrometallurgical processing of polish copper concentrates. Physicochem. Probl. Miner. Process 2011. Vol. 46. P. 207-218.

9. Tinkler O., Shiels D., Soderstrom M. The ACORGA ${ }^{\circledR}$ OPT series: comparative studies against aldoxime: ketoxime reagents. Hydrometallurgy Conference 2009, The Southern African Institute of Mining and Metallurgy. 2009. P. 273-281.

10. Аксёнов, А.В., Васильев А.А. Способ вскрытия тонковкрапленного золота из упорного сульфидного сырья на основе сверхтонкого измельчения и атмосферного окисления. Материалы научно-практической конф. «Перспективы развития, экологии и автоматизации химических, пищевых и металлургических производств». Иркутск, ИрГТУ, 2009. С. 9-11. [Aksenov 
A.V. Vasilyev A.A. Approach to finely disseminated gold liberation from refractory sulphide materials using ultrafine grinding and atmospheric oxidation. Proceedings of Conference "Prospects for further development, ecology and automatization of chemical, food and metallurgical production". Irkutsk, INRTU, 2009. P. 9-11. (In Russ.)]

11. Набиулин Р.Н., Богородский А.В., Баликов С.В., Емельянов Ю.Е. Атмосферное окисление золотомедного флотоконцентрата. Сборник тезисов докладов восьмого международного конгресса «Цветные металлы и минераль 2016». Красноярск. 2016. С. 462-463. [Nabiulin R.N., Bogorodsky A.V., Balikov S.V., Yemelyanov, Yu.E. Atmospheric oxidation of a gold-copper float concentrate. Proceedings of VIII International Congress "Nonferrous metals and minerals". Krasnoyarsk, 2016. P. 462-463. (In Russ.)] 